\title{
HIV/AIDS in Africa - a role for the mental health practioner?
}

In the last few decades psychiatric discourse has undergone an important change in its scope and focus. During the heady days of psychoanalytic hegemony, psychiatrists were willing to prognosticate or pontificate on just about anything, from individual neurosis through to social maladies, from medicine to literature, from the unconscious to the conscious. Nowadays, psychiatry self-consciously emphasises its origins as a medical discipline, focuses its diagnostic efforts on operationally defined psychiatric disorders, and argues the value of specific pharmacotherapies and psychotherapies in treating these conditions.

There is plenty to keep the medically orientated psychiatrist busy. Neuropsychiatric disorders comprise 5 of the 10 most disabling of all medical disorders.' Depression, anxiety disorders, and substance use are the most prevalent psychiatric disorders; these are significantly underdiagnosed and undertreated in both the developed and the developing world. ${ }^{2}$ Nevertheless, advances in the neurosciences have led to new knowledge on the psychobiology of the major psychiatric disorders, and an ever-expanding range of effective pharmacotherapies and psychotherapies are now available for their treatment.

At the same time the psychiatrist cannot but grapple with the broader issues. During apartheid much was written about the effects of social repression on individuals' mental health. With democracy, questions were raised about whether processes such as the Truth and Reconciliation Commission would help those who had experienced gross human rights violations, and who now suffered from conditions such as post-traumatic stress disorder (PTSD). ${ }^{3}$ Ten years after the end of apartheid violence is an endemic phenomenon in South African society, so that physicians need to screen rigorously for exposure to trauma and for the presence of post-traumatic sequelae, and to devote their attention to broader social interventions that can help decrease risk factors (e.g. poverty and gender inequity) for violence. ${ }^{4}$

But the biggest mental health challenge in Africa, now and in the foreseeable future, is HIV/AIDS. First, there is good evidence from studies in the developed world, and in Africa, that the prevalence of psychiatric disorders is increased in people living with HIV/AIDS (PWA); HIV/AIDS is associated with depression, delirium, and ultimately dementia. ${ }^{5}$ Second, although there have been few studies of psychopathology in HIV orphans in Africa, it can be expected that children who face multiple losses and stressors will experience significant developmental disruptions and ultimately high levels of psychiatric disorder. ${ }^{6}$ Third, many members of society, including caregivers of people with HIV and people who are untested but aware that they are at great risk, may well be at risk for developing psychiatric disorders.' Fourth, the presence of stressors and psychiatric disorders, such as PTSD, may well put people at risk for developing $H \mathrm{IV}^{8}$, or for more rapid progression of the disease. 9,10

The experience of trauma in Africa has had a number of important lessons. First, suffering should not be equated with psychiatric disorder; many have suffered trauma, but not psychiatric disorder." Similarly, resilience should not be underestimated. Even among those suffering from psychiatric disorders, there are different levels of functioning, with some people able to maintain relatively high levels of family and occupational function. ${ }^{12}$ Third, effective leadership from a range of stakeholders can play a much more important role than the mental health care community. Strong leaders, together with community mobilisation, can effect changes in the fundamental factors that increase the risk of violence, and can enhance the extent to which people are able to cope with adverse circumstances. While it is interesting to consider whether perpetration of violence is primarily mediated in part by individual psychopathology, ${ }^{13}$ given its social roots, what is needed to end apartheid or other kinds of violence is a broad change in community knowledge, attitudes, and practices.

These lessons also apply to HIV/AIDS. There will be many who suffer from HIV/AIDS directly or indirectly; it is reductionistic merely to equate such suffering with particular kinds of psychopathology. We can expect that HIV/AIDS will significantly increase the burden of mental illness in South Africa and the need for psychiatric treatment resources, but we can also hope that many of those with HIV/AIDS /witness the 
remarkable work of the Treatment Action Campaign) can nevertheless make significant contributions to taking action against the further spread of the virus. However, ultimately, to be successful, work on HIV/AIDS will require significant leadership from all sectors of society. ${ }^{6}$ While it is interesting to speculate whether denial of HIV/AIDS reflects individuals' rigidity in thought, at the end of the day what is crucially needed is a reversal of community knowledge, attitudes and practices regarding HIV/AIDS.

Reversing community knowledge, attitudes, and practices with regard to violence and to sex can certainly draw on scientific principles. A psychoanalytic perspective can comment readily on how fundamental sex and aggression are, and how resistance to change will spring up at every turn. An evidencebased perspective would encourage rigorous data collection, and the formulation of evidence-based policy. Nevertheless, the question of how to effect social changes optimally is too important to be left in the hands of medical specialists; we can lead by example /witness the courageous stance of Professor William Makgoba ${ }^{14}$ I, but we must hope that many outside of medicine will take up the work against HIV/AIDS on behalf of our patients. Africa stands at a crucial juncture; HIV promises to further decimate our people and destabilise our communities, but it also provides an important opportunity for ensuring that we tackle many of our social ills (e.g. poverty and gender inequityl in a constructive way.

\section{Dan J Stein}

Soraya Seedat

Robin A Emsley

Department of Psychiatry

Stellenbosch University

W Cape

\section{Benjamin O Olley}

\author{
Department of Psychiatry \\ Ibadan University \\ Nigeria
}

\section{References}

1. Murray CJL Lopez AD. Global Burden of Disease: A Comprehensive Assessment of Mortality and Morbidity from Diseases, Injuries and Risk Factors in 1990 and Projected to 2020. Vol I. Harvard: World Heal h Organization, 1996.

2. World Heal h Organization. The World Health Report 2001: Mental Health: New Understanding, New Hope. Geneva: WHO, 2001.

3. Stein DJ. Psychiatric aspects of he Tru h and Reconciliation Commission in Sou h Africa. BrJ Psychiatry 1998; 173: 455-458

4. Stein, DJ, Seedat S, Emsley RA. Violence in the world - what is a doctor to do? S Afr Med J 2002; 92: 789-790.

5. Olley BO, Gxamza F, Seedat S, et al. Psychopa hology and coping in recently diagnosed HIV/AIDS patients - the role of gender. S Afr Med J 2003; 93: 928931.

6. United Nations AIDS Organisation. Accelerating Action against AIDS in Africa. Geneva: UNAIDS, 2003

7. Freeman M. HIV/AIDS in developing countries: heading towards a mental health and consequent social disaster? South African Journal of Psychology 2004; 34: 139-159.

8. Hutton HE, Treisman GJ, Hunt WR, et al. HIV risk behaviors and their relationship to posttraumatic stress disorder among women prisoners. Psychiatr Serv 2001; 52: 508-513.

9. Evans, DL, Leserman J, Perkins DO. Severe life stress as a predictor of early disease progression in HIV infection. Am J Psychiatry 1997; 154: 624-629.

10. Kopnisky KL, Stoff DM, Rausch DM. Workshop report: the effects of psychological variables on the progression of HIV-1 disease. Brain Behav Immun 2004; 18: 246261.

11. Kaminer D, Stein, D」, Mbanga I, Zungu-Dirwayi N. The Tru h and Reconciliation Commission (TRC) in South Africa: Relation to psychiatric status and forgiveness among survivors of human rights abuses. Br J Psychiatry 200 1; 178: 373-377.

12. Richardson GE. The metatheory of resilience and resiliency. J Clin Psychol 2002; 58: $307-321$.

13. Kaminer D, Stein DJ. Sadistic personality disorder in perpetrators of human rights abuses: A South African case study. J Personality Disord 200 1; 15: 474-486.

14. Makgoba MW. HIV/AIDS: he peril of pseudoscience. Science 2000; 288: 1171

Reprinted from he South African Medical Journal (2005; 95: 167-168) 